\title{
Microstructural brain abnormalities, affective temperaments, and suicidal behavior in patients with major depression
}

\author{
Gianluca Serafini ${ }^{1}$, Mario Amore ${ }^{1}$, Zoltan Rihmer ${ }^{2}$ \\ ${ }^{1}$ Department of Neuroscience, Rehabilitation, Ophthalmology, Genetics, Maternal and Child Health, Section of Psychiatry, \\ University of Genoa, 16132 Genoa, Italy. \\ ${ }^{2}$ Department of Clinical and Theoretical Mental Health, Semmelweis University, Budapest, Hungary and National Institute of \\ Psychiatry and Addictions, H-1085 Budapest, Hungary.
}

\section{A B S T R A C T}

\begin{abstract}
According to magnetic resonance imaging (MRI) studies, brain white matter (WM) abnormalities have been suggested to play a critical role in the pathogenesis of major depressive disorder (MDD) and related suicidal behavior. However, MRI findings may be limited by low spatial resolution; therefore, an important contribution to the understanding of the role and significance of WM alterations derived by the development of the most recent magnetic resonance techniques, such as diffusion tensor imaging (DTI). Several DTI studies reported an association between altered WM integrity and MDD/suicidal behavior. Microstructural WM abnormalities may be located in neural circuits critically implicated in emotional processes and mood regulation resulting in enhanced vulnerability to psychiatric morbidity. WM abnormalities detected using DTI may contribute to functional deficits and help to clarify the pathophysiological mechanisms underlying MDD as well as suicidal behavior. By a clinical point of view, research also suggested that affective temperaments may play a relevant role in the psychopathological characteristics of mood disorders, clinical trajectory of episodes and polarity, long-term outcome and suicidality. Unfortunately, only few studies investigated the association between affective temperaments and WM abnormalities and discussed their possible implications in patients with MDD and suicidal behavior. Using a comprehensive search of Medline database, the aim of the present study was to critically review the current literature on the association between WM alterations as assessed by MRI and DTI techniques, affective temperaments, MDD and suicidal behavior.
\end{abstract}

Key words: Affective temperaments, major depression, microstructural white matter lesions, neuroimaging techniques, suicidal behavior

\section{INTRODUCTION}

Major depressive disorder (MDD) is a widespread condition associated with functional impairment and significant disability. Patients with MDD usually experience frequent recurrences, incomplete recovery between episodes, residual symptoms, poor psychosocial adjustment and high risk of suicide. ${ }^{[1,2]}$

Corresponding Author: Dr. Gianluca Serafini,

Department of Neuroscience, Rehabilitation, Ophthalmology, Genetics, Maternal and Child Health, Section of Psychiatry, University of Genoa, IRCCS San Martino, Largo Rosanna

Benzi 10, 16132 Genoa, Italy.

E-mail: gianluca.serafini@unige.it

\begin{tabular}{|l|l|}
\hline \multicolumn{2}{|c|}{ Access this article online } \\
\hline Quick Response Code: & \\
\hline & Website: \\
& www.nnjournal.net \\
& \\
& \\
\end{tabular}

Suicidal behavior is a complex and multidimensional condition aimed at self-destruction determining a serious distress in the community and among all those who are near the victim; however, as suicide may be considered a rare social event, its prediction at the individual level is very difficult. Untreated unipolar MDD is one of the most relevant risk factors related to completed suicide accounting for $56-87 \%$ of the cases. ${ }^{[2]}$ Importantly, suicide may be considered a state- and severity-dependent phenomenon, and this is also demonstrated by the fact that suicidality significantly decreases after clinical recovery. ${ }^{[2]}$ Although identifying some clinical, psychological and psychosocial risk

This is an open access article distributed under the terms of the Creative Commons Attribution-NonCommercial-ShareAlike 3.0 License, which allows others to remix, tweak, and build upon the work non-commercially, as long as the author is credited and the new creations are licensed under the identical terms. For reprints contact: nn_editor001@nnjournal.net

Cite this article as: Serafini G, Amore M, Rihmer Z. Microstructural brain abnormalities, affective temperaments, and suicidal behavior in patients with major depression. Neuroimmunol Neuroinflammation 2015;2:200-14.

Received: 13-08-2015; Accepted: 06-04-2015 
factors may help to recognize those depressed or nondepressed individuals who are at increased high risk for suicide, ${ }^{[3]}$ the mechanisms underlying this complex behavior as well as the link with psychopathology are still poorly understood.

White matter hyperintensities (WMHs) appear as hyperintense signals on T2-weighted magnetic resonance imaging (MRI) and represent ependymal loss and differing degrees of myelination in the brain. ${ }^{[4,5]}$ WMHs, depending on their localization, may be classified as periventricular WMHs and deep WMHs, with the latter usually having a vascular etiology. Degenerative changes in brain white matter (WM) have been associated with both mood disorders and suicidal behavior in children as well as young adults, ${ }^{[6-9]}$ however they seem to be not specific of patients with first-episode psychotic disorders. ${ }^{[10]}$

Diffusion tensor imaging (DTI) studies can identify microstructural WM abnormalities with high special resolution enabling the characterization of WM tracts that relate to critical brain regions implicated in mood regulation. According to the current literature, there are many recent DTI studies examining WM networks abnormalities in patients with $\mathrm{MDD}^{[11-14]}$ as well as in those with suicidal behavior. ${ }^{[15-18]}$ Specifically, some DTI studies reported the existence of frontolimbic WM abnormalities in treatment-naive first-episode MDD individuals ${ }^{[19-22]}$ and adolescents with MDD $^{[23-24]}$ whereas other studies investigated the role of WM microstructural alterations in patients with melancholic MDD characteristics ${ }^{[25,26]}$ or the effect of treatments on WM integrity in subjects with MDD. ${ }^{[27-30]}$ Further, DTI studies also investigated the impact of WM abnormalities during the different illness phases (e.g. subclinical depression, throughout the acute MDD episode, at the end of therapy and subsequent follow-up). ${ }^{[31-33]}$

Taylor et $a .^{[34]}$ hypothesized that patients with WM lesions may be at higher risk for developing mood disorders and suicide due to possible disruption of neuroanatomical pathways. Mood regulation depends on the complex extensive connections between the prefrontal cortex, amygdala-hippocampus complex, thalamus and basal ganglia. ${ }^{[35]}$ Mood disorders range from subthreshold affective temperamental traits as measured by the Temperament Evaluation of Memphis, Pisa, Paris and San Diego-auto-questionnaire (TEMPS-A) ${ }^{[36]}$ up to mood disorders (of minor and major severity) and severe affective psychosis. ${ }^{[37-40]}$ Affective temperaments may significantly influence the psychopathological characteristics of mood disorders, in particular, the clinical trajectory of episodes and polarity, symptomatology, long-term course, suicidality, and medication adherence. ${ }^{[37,38,40-44]}$
To date, the association between microstructural WM abnormalities, affective temperaments, and suicidal behavior in patients with MDD is poorly understood. Therefore, this paper aims to critically review the current literature about this association.

Studies investigating the presence and significance of WM abnormalities and their link with affective temperaments in patients with major depression and suicidal behavior were retrieved from Medline databases. The reference lists of these publications were further investigated to find additional relevant studies. An extensive search was carried out for research published between January 1980 and October 2014 using the following search terms: "'major depressive disorder" OR "MDD” OR “Major depression”) AND ("Affective temperaments") AND ("White matter hyperintensities" OR "microstructural white matter lesions" OR "white matter abnormalities" OR "white matter changes signals") AND ("MRI” OR "magnetic resonance imaging”) AND ("Diffusion Tensor Imaging”) OR ("DTI"). Only studies published in English were included. We did not analyze in the present overview studies including patients with bipolar depression nor patients with treatment-resistant major depression.

\section{THE ROLE OF MICROSTRUCTURAL WM BRAIN ABNORMALITIES AS ASSESSED BY MRI IN PATIENTS WITH UNIPOLAR MAJOR DEPRESSION}

Microstructural brain lesions, especially in the context of WM integrity, may be frequently found in patients with unipolar major depression. ${ }^{[45]}$ Based on their systematic review and meta-analysis, cross-sectional subgroup analyses showed that deep WMHs resulted significantly associated with major depression whereas periventricular and overall WMHs did not. In addition, according to longitudinal subgroup analyses, overall WMHs were significantly associated with major depression but deep WMHs did not.

Microstructural WMbrainalterations are neuropathologically characterized by decreased oligodendrocyte density, molecular changes in intercellular cell adhesion molecule expression levels and possible ischemia. ${ }^{[46]}$

In another meta-analysis, Kempton et al. ${ }^{[47]}$ reported that MDD was associated with lateral ventricle enlargement; larger cerebrospinal fluid volume; smaller volumes of the basal ganglia, thalamus, hippocampus, frontal lobe, orbitofrontal cortex, and gyrus rectus compared with the structures of the healthy brain. Furthermore, during depressive episodes patients reported significantly smaller hippocampal volume than patients during remission. 
Gender differences in WM disease of patients with MDD in late life have been recently described by Dotson et al. ${ }^{[48]}$ The authors reported that depressive symptoms predicted increased WMHs rates in men but not in women. A higher rate of WMHs was commonly reported in individuals with late-onset depression (LOD) when compared with healthy elderly controls and subjects with early-onset depression (EOD). ${ }^{[49-52]}$ Salloway et al. ${ }^{[53]}$ reported that both deep WMHs and periventricular WMHs were significantly more severe in the LOD group than EOD group. More recently, Gunning-Dixon et al. ${ }^{[54]}$ found that 22 patients who did not remit following escitalopram treatment had significantly greater WMHs on MRI than 20 remitted patients and 25 elderly controls. In addition, Takahashi et al. ${ }^{[55]}$ reported that patients with LOD showed a higher rate of deep WMHs and more severe pathological changes especially in the bilateral frontal areas and left parieto-occipital area compared with EOD. Compelling evidence suggested that deep WMHs are more severe in LOD than in healthy controls. ${ }^{[50,56,57]}$

The frontal lobes have mutual fiber communications with subcortical nuclei, such as the thalamus, basal ganglia, and amygdala via WM projections mediating emotional processing of information and regulation of emotional states. It has been suggested that dysfunctions of the frontal lobes may be caused by subcortical WM lesions triggering the emergence and maintenance of mood disorders. ${ }^{[58]}$

There are also studies suggesting that the presence of WM lesions may be associated with clinical severity and treatment responsiveness. In 12-week, randomized clinical trial comparing Sertraline with Nortriptyline, Sneed et al. ${ }^{[59]}$ also tested the hypothesis that remission from geriatric depression may depend on lesion volume by region of interest and found that patients with higher deep WMHs were 7.14 times more likely to not remit after antidepressant treatment compared to patients with lower deep WMHs. The authors also suggested that those having higher periventricular VMHs and total volumes may be 4.17 and 5.00 times more likely to not remit, respectively.

Increased severity of WM lesions is also associated with a more chronic outcome, ${ }^{[46,60-62]}$ poorer response to antidepressant medications, ${ }^{\left[{ }^{[6-65]}\right.}$ and long-term disability ${ }^{[66]}$ in depressed patients. WMHs are also generally associated with cognitive decline in various domains, particularly executive skills, attention, and mental speed. ${ }^{[63,67-69]}$

In addition, Sheline et al. ${ }^{[70]}$ suggested the critical and strategic importance of WMHs location in LOD. The authors reported that 83 depressed subjects showed greater WMHs in the superior longitudinal fasciculus (SLF), fronto-occipital fasciculus, uncinate fasciculus, extreme capsule, and inferior longitudinal fasciculus that were associated with both cognitive (e.g. episodic memory, processing speed, and executive functions) and emotional functions when compared with 32 healthy controls.

Finally, there are also few studies reporting the association between WMHs and suicidal behavior in MDD patients. In 2012, Serafini et al. ${ }^{[71]}$ reported that among 85 adult outpatients with chronic headache, patients with periventricular WMHs were 1.06 times more likely to report fewer depressive symptoms than patients without PWMHs suggesting that $\mathrm{WMH}$ lesions were associated with less depression severity. However, no association between WMHs and suicidal behavior was found. Interestingly, in a meta-analysis including four MRI studies, a significantly higher number of suicide attempters was reported to have WMHs compared to non-attempters. ${ }^{[72]}$ Specifically, unipolar depressed patients who had attempted suicide were 1.9 and 2.1 times, respectively, more likely to have deep WMHs and periventricular WMHs than nonattempters.

In addition, in a cohort of 99 unipolar/bipolar patients, Pompili et al. ${ }^{[73]}$ reported after logistic regression analyses that periventricular WMHs were robustly associated with suicidal behaviors after controlling for age. Importantly, the same research group ${ }^{[9]}$ had previously found in a smaller $(n=65)$ cohort of unipolar/bipolar inpatients an higher WMHs prevalence in subjects with past suicide attempts than in those without.

In 2005, Ehrlich et al. ${ }^{[8]}$ suggested a higher prevalence of periventricular WMHs in subjects with past suicide attempts among a cohort of 102 young psychiatric inpatients with MDD. Furthermore, a significant association between WMHs and higher prevalence of past suicide attempts in 48 unipolar depression group had been previously reported. ${ }^{[7]}$ The same research group ${ }^{[6]}$ found that youths with deep WMHs mainly located in the parietal and frontal lobes have a significantly higher prevalence of reported past suicide attempts.

WMHs have been commonly reported in both patients with MDD and suicidal behavior; however, the clinical significance of these lesions is still poorly understood as they may be also found in non-depressed individuals with cerebrovascular risk factors such as hypertension, ${ }^{[56,57,67]}$ diabetes, myocardial infarction or coronary artery disease, and smoking. ${ }^{[57,74]}$ 
THE ROLE OF MICROSTRUCTURAL WM BRAIN ABNORMALITIES AS ASSESSED BY DIFFUSION TENSOR IMAGING IN PATIENTS WITH UNIPOLAR MAJOR DEPRESSION

An important contribution to the understanding of the role and significance of WMHs in patients with mood disorders arrived from the most recent magnetic resonance techniques such as DTI. Since 2002, when Alexopoulos et al. ${ }^{[75]}$ reported an association between lower fractional anisotropy (FA) of the right and left frontal WM regions with a low remission rate, several other DTI studies found an association between microstructural WM abnormalities and MDD. These authors identified for the first time the presence of microstructural WM abnormalities lateral to the anterior cingulate and hypothesized that they were associated with a low rate of remission in 13 patients with geriatric MDD.

Very recently, Qin et al. ${ }^{[11]}$ reported that the hubs of WM brain networks consisting of the bilateral dorsolateral part of superior frontal gyrus, left middle frontal gyrus, bilateral middle temporal gyrus, and bilateral inferior temporal gyrus may accurately distinguish patients with MDD from healthy controls. Lai and $\mathrm{Wu}^{[13]}$ suggested that 44 patients with MDD had significantly lower FA values in the left SLF as well as the right anterior thalamic radiation when compared with 27 healthy controls. These patients had also increased radial diffusivity values in the bilateral SLF and decreased axial diffusivity values in the bilateral anterior thalamic radiation. The authors suggested that $F A$ values resulted negatively associated with depression severity in the SLF, and illness duration in the right SLF and anterior thalamic radiation.

Another recent DTI study ${ }^{[19]}$ found that adolescents with depression had significantly lower FA and higher radial diffusivity in bilateral uncinate fasciculus. According to tract-based spatial statistics findings, lower WM FA values have been associated with the limbic-cortical-striatal-thalamic circuit, corpus callosum, and anterior and superior corona radiata.

In 2007, Li et al. ${ }^{[76]}$ found microstructural alterations in prefrontal WM occurring early in the course of MDD of 19 first-episodes, untreated MDD young adults relative to healthy controls. In a similar cohort (14 first-episode, treatment-naive young adult MDD subjects), Ma et al. ${ }^{[77]}$ found significantly lower FA values than controls in the WM of the right middle frontal gyrus, left lateral occipitotemporal gyrus, and subgyral and angular gyri of the right parietal lobe. Moreover, Taylor et al. ${ }^{[78]}$ reported significantly lower
FA values in the right superior frontal gyrus WM of depressed patients than controls.

de Kwaasteniet et al. ${ }^{[21]}$ demonstrated that WM integrity of the uncinate fasciculus was reduced and that functional connectivity between the subgenual anterior cingulate cortex and medial temporal lobe was increased in 18 MDD patients when compared with 24 healthy controls. A negative correlation between uncinate fasciculus integrity and subgenual anterior cingulate cortex functional connectivity with the bilateral hippocampus was also observed only in MDD subjects.

Previously, Bae et al. ${ }^{[79]}$ reported significantly lower FA values in WM of the right anterior cingulate cortex, bilateral superior frontal gyri and left middle frontal gyrus of 106 elderly depressed subjects. Furthermore, a significant reduction in FA values of widespread regions of the frontal and temporal lobes in 13 patients with LOD was found by Nobuhara et al. ${ }^{\left[{ }^{[0]}\right.}$ Interestingly, the severity of depression was inversely related to reduce FA values of the inferior frontal region.

Zhang et al. ${ }^{\left[{ }^{[1]}\right.}$ have previously reported that in a cohort of 21 MDD subjects depression severity had a significant negative correlation with normalized number of fibers in the right uncinate fasciculus. Similarly, Steffens et al. ${ }^{[82]}$ reported a significant association between left uncinate fasciculus FA and resting state functional connectivity between the left ventrolateral prefrontal cortex/left amygdala and between the left ventrolateral prefrontal cortex/left hippocampus. A significant negative correlation has also been suggested between left ventromedial prefrontal cortex-caudate resting state functional connectivity and left, but not right, uncinate fasciculus FA in 24 older patients remitted from MDD.

Another DTI study analyzed the integrity of the WM of corpus callosum and its sub-regions in 16 subjects affected by MDD and 16 age- and gender-matched healthy controls. ${ }^{[23]}$ The authors reported that the corpus callosal area of the genu was smaller in MDD participants than in 16 healthy controls.

Similar findings have been replicated in adult subjects with treatment-responsive MDD by Guo et al. ${ }^{[83]}$ The authors found lower FA values in the bilateral internal capsule, genu of corpus callosum, bilateral anterior corona radiata, and right external capsule of 22 patients compared to 19 healthy subjects.

Recently, Korgaonkar et al. ${ }^{[29]}$ suggested that anterior cingulate-limbic WM may be a useful predictor of antidepressant treatment outcome in 74 MDD patients who completed 8-week antidepressant treatment. The 
authors reported that altered connectivity for the cingulum part of the cingulate and stria terminalis tracts significantly predicted remission. Hayakawa et al. ${ }^{[31]}$ reported a positive correlation between Center for Epidemiologic Studies Depression Scale (CES-D) scale score and radial diffusivity in the right anterior cingulum of 21 subclinically depressed women compared with 21 matched controls.

Another recent report ${ }^{[12]}$ suggested that in $95 \mathrm{MDD}$ outpatients compared to 102 matched control subjects structural connectivity alterations between nodes of the default mode network and frontal-thalamo-caudate areas (having an important role in emotional and cognitive processing) may play a critical role in the pathophysiology of MDD.

Structural connectivity alterations were also observed in the brainstem and the amygdala in $95 \mathrm{MDD}$ patients compared to 34 gender-matched controls ${ }^{[14]}$ whereas lower FA values in the body of the corpus callosum, increased radial and mean diffusivity were found after whole-brain analysis. In addition, higher FA values in the uncinate fasciculus together with increased axial diffusivity, reduced radial diffusivity were reported after region-of-interest analysis by Aghajani et al. ${ }^{[84]}$

A preliminary report ${ }^{[24]}$ on 17 MDD adolescents suggested decreased WM integrity in the anterior cingulum and anterior corona radiata compared to 16 matched controls. Depression severity has been correlated with reduced WM integrity in the genu of corpus callosum, anterior thalamic radiation, anterior cingulum, and sagittal stratum. Similarly, Bessette et al. ${ }^{[20]}$ reported significantly lower FA of the frontal lobe, bilateral anterior/posterior limbs of the internal capsules, left external capsule, right thalamic radiation and left inferior longitudinal fasciculus in 31 MDD adolescents when compared with 31 healthy volunteers. A first DTI study ${ }^{[85]}$ found altered WM microstructure in frontolimbic neural pathways of 14 MDD adolescents compared with 14 healthy controls.

Furthermore, Tha et al. ${ }^{[22]}$ reported clusters of FA decrease in several brain regions (e.g. the bilateral frontal WM, anterior limbs of internal capsule, cerebellum, left putamen and right thalamus) in a limited cohort of nine patients with MDD who are not taking antidepressant medications.

Interesting findings were also found in melancholic subtype of MDD. ${ }^{[25]}$ The authors suggested that MDD melancholic patients $(n=12)$ had lower mean FA in the right ventral tegmental area-lateral orbitofrontal cortex and ventral tegmental area-dorsolateral orbitofrontal cortex connections compared to 21 healthy controls.
Depression total scores were negatively correlated with mean-FA of these brain regions.

Structural abnormalities of cortico-cortical WM motor pathways have been also suggested in 2012 by Bracht et al. ${ }^{[26]}$ in a study of $21 \mathrm{MDD}$ patients relative to 21 healthy controls. They observed that patients had lower activity levels and showed increased mean diffusivity in pathways linking left presupplementary motor area and supplementary motor area, and right supplementary motor area and primary motor cortex. Notably, a negative association between activity level and mean diffusivity of the left dorsolateral prefrontal cortex-pre-supplementary motor area connection was observed only in MDD patients with low activity levels.

In addition, Osoba et al. ${ }^{[32]}$ reported significant FA deficits in the right parietal WM of 20 MDD patients whereas severity of depression has been associated with increased thalamic FA in centromedian tracts and decreased FA in mediodorsal and dorsolateral prefrontal cortex tracts. Lower activity levels in frontal WM regions and posterior cingulum when compared with 21 matched healthy controls were also found by Walther et $a .^{\left[{ }^{[86]}\right.}$ in a cohort of 21 medicated patients with MDD. Depressed subjects also reported negative associations of FA and activity levels below the left primary motor cortex and left parahippocampal gyrus WM.

In 2012, Cole et al. ${ }^{[87]}$ reported that MDD was associated with widespread reductions in WM integrity of the corpus callosum, SLF and anterior corona radiate in 66 patients with recurrent major depression compared to 66 controls. The authors suggested that WM integrity of the corpus callosum was negatively correlated with increasing symptom severity.

Using a 3T scanner DTI, Colloby et al. ${ }^{[88]}$ investigated 68 subjects (30 healthy individuals, and 38 depressed individuals) and found a loss of WM integrity within the frontal, temporal and midbrain fibers. Patients with LOD demonstrated significant lower FA compared with older healthy subjects due to the possible disruption of limbic-orbitofrontal networks. However, after conducting regression analyses, the authors did not find a significant association between DTI parameters and current depressive symptoms.

Moreover, Korgaonkar et al. ${ }^{[89]}$ reported the presence of WM integrity deficits in 11 melancholic MDD subjects relative to 39 healthy controls postulating the existence of a pattern of reduced myelination or other degenerative changes whereas Wu et al. ${ }^{[00]}$ reported a significantly lower FA in the right SLF within the frontal lobe, right middle frontal and left parietal WM 
when investigating 23 single-episode, medication-naive MDD subjects relative to 21 healthy controls.

Lower FA values in the bilateral medial frontal gyri, right subgyral frontal and temporal lobes, left middle frontal, and cingulate gyri have been reported by Ouyang et al. ${ }^{[91]}$ in $18 \mathrm{MDD}$ patients compared to 18 controls.

Abnormalities of WM integrity, especially within cortical-subcortical neural circuits, have been suggested to play a key role in the pathophysiology of MDD. Reduced FA values in the left WM anterior limb of the internal capsule (ALIC), right parahippocampal gyrus, and left posterior cingulate cortex in 25 first-episode, treatment-naive young adult MDD patients compared with 25 healthy controls have been reported by Zhu et al. ${ }^{[92]}$ Interestingly, the severity of depressive symptoms was negatively correlated with the reduced FA values of the left ALIC suggesting a crucial role of this brain region in the pathogenesis of MDD.

Lamar et al. ${ }^{[93]}$ reported an association between WM damage and endorsed depressive symptoms in 79 euthymic older adults whereas Zou et al. ${ }^{[94]}$ observed a significant decrease in FA of the left hemisphere, including the left ALIC and inferior parietal portion of the SLF in 45 patients with MDD compared with 45 healthy controls. Finally, lower FA of the rostral/ dorsal anterior cingulate, dorsolateral prefrontal cortex, genu of the corpus callosum, WM adjacent to the hippocampus, multiple posterior cingulate cortex regions, and insular WM, neostriatum and midbrain together with temporal and parietal regions were found in 23 individuals who failed to remit compared to 25 patients who recovered from depression. ${ }^{[95]}$

Meta-analytic evidence of DTI studies ${ }^{[96]}$ also confirmed the association between WM integrity abnormalities and MDD. Reduced FA in the WM fascicles connecting the prefrontal cortex within cortical (frontal, temporal and occipital lobes) and subcortical areas (amygdala and hippocampus) supported the involvement of these brain areas in the pathogenesis of MDD. Similar findings were reported in a previous meta-analysis when Murphy and Frodl ${ }^{[97]}$ found reduced WM FA values in SLF and increased FA values in the fronto-occipital fasciculus in depressed patients compared to controls.

There are also DTI studies demonstrating the positive effect of treatments on WM integrity in patients with MDD. Lyden et al. ${ }^{[27]}$ suggested that WM microstructure abnormalities in frontal and limbic regions of 20 MDD patients are modulated by electroconvulsive therapy (ECT). They found significant FA increases of the dorsal fronto-limbic circuits encompassing the anterior cingulum, forceps minor, and left SLF in patients receiving ECT compared to healthy controls. The authors also reported significant reductions in radial and mean diffusivity of the anterior thalamic radiation related to therapeutic response in MDD patients. In another DTI study, Taylor et al. ${ }^{[98]}$ suggested that 74 subjects who were responders to Sertraline reported higher FA values in the superior frontal gyri and anterior cingulate cortices bilaterally; however, there is no significant association between apparent diffusion coefficient measures and remission.

Furthermore, Nobuhara et al. ${ }^{[99]}$ reported improvements of WM integrity in frontal brain regions after ECT treatment in 8 late-life depressed patients with significant frontal and temporal FA reductions compared with 12 healthy age-matched controls.

In another report, Wang et al. ${ }^{[3]}$ suggested a significant reduction of the 17-item Hamilton depression rating scale in 21 depressed patients after 4-week guided imagery psychotherapy. Significantly increased FA in the right thalamus was reported in depressed individuals compared to healthy controls. Changes in WM have been also described after left repetitive transcranial magnetic stimulation by Kozel et al. ${ }^{[100]} \mathrm{A}$ mean (although not significant) increase was found in the left prefrontal WM in 8 depressed patients.

Recently, Hoogenboom et al. ${ }^{[28]}$ found that failure to achieve remission was associated with lower medial body of the fornix FA among 92 MDD patients (of which 29 were nonremitters, 26 partial-remitters, and 37 full-remitters).

Not all studies supported the existence of WM alterations as assessed using DTI techniques in MDD patients. Choi et al. ${ }^{[30]}$ found no significant differences in FA, radial diffusivity, mean diffusivity, and axonal diffusivity using voxel-based morphometry or tract-based spatial statistics approach in 134 medication-free MDD patients compared to 54 healthy controls.

Moreover, Bezerra et al. ${ }^{[101]}$ reported no significant differences among FA or mean diffusivity values between depressed and non-depressed elderly individuals with or without mild/moderate MDD. Abe et al. ${ }^{[102]}$ also suggested no significant difference between 21 right-handed patients and 42 age- and gender-matched controls for FA and whole WM volume. Only a trend of negative correlation between FA and total days in the right anterior cingulate and left frontal WM was reported in this study.

Similarly, Kieseppä et al. ${ }^{[103]}$ investigated 16 MDD patients and found only a trend for lower values of FA 
in the left sagittal stratum, and reduced FA in the right cingulate cortex/posterior body of corpus callosum compared to 20 controls.

\section{WMHS AND AFFECTIVE TEMPERAMENTS: CLINICAL IMPLICATIONS REGARDING MDD AND SUICIDALITY}

Few studies investigated the association between affective temperaments and WMHs as well as their possible implications on suicidal risk.

Weber et al. ${ }^{[104]}$ conducted a 2-year follow-up study in a cohort of 28 EOD elderly patients and observed increased neuroticism factor, anxiety facet scores, and reduced warmth and positive emotions facet scores only at baseline compared to 48 controls. Significantly higher depression facet scores at both baseline and after 2 years independently of depressive relapse were also reported in EOD elderly patients than controls. In 2010, the same research group ${ }^{[105]}$ reported no significant group differences in WMH rates between 38 EOD and 62 controls. Importantly, EOD was associated with a significant increase of neuroticism and decrease of extraversion facet scores as assessed by five-factor personality dimensions.

Serafini et al. ${ }^{[106]}$ found that patients with higher dysthymia and lower hyperthymia scores (as assessed by TEMPS-A) were more likely to have higher suicidal risk, more recent suicide attempts, and more deep WMHs than patients with higher hyperthymia and lower dysthymia scores. In this study, different temperament characteristics are reflected by MRI findings. The mentioned results replicate the findings of prior studies showing that depressive, cyclothymic, irritable and anxious temperaments may be considered risk factors for suicidal behavior whereas hyperthymic temperament is a protective factor, at least for suicide attempters. ${ }^{[106,107]}$

There are also DTI studies analyzing the presence of WM abnormalities in healthy individuals. Picerni et $a l^{[108]}$ investigated the relationship between cerebellar macro- and micro-structural variations detected by DTI and temperamental traits assessed using temperament and character inventory (TCI) in 100 healthy individuals. The authors found increased WM FA associated with higher novelty-seeking scores suggesting that macro- and micro-structural characteristics of posterior vermis play a critical role in novelty-seeking behaviors. In a previous report, the same research group suggested that the scores of the four temperamental scales of TCI were positively associated with the volumes of cerebellar WM.[109] Specifically, it has been suggested that novelty seeking scores were positively associated with WM volume whereas harm avoidance scores were negatively associated with WM volume in a cohort of 125 healthy participants.

Moreover, Bjørnebekk et al. ${ }^{[110]}$ reported an association between social reward dependency and WM microstructure in 263 healthy volunteers. In detail, the authors found that increased reward dependence was associated with reduced FA in anterior brain areas suggesting that WM fiber tract properties may significantly modulate individual differences in social reward. However, no associations were found between novelty seeking behavior as assessed by TCI and DTI indices.

Westyle et al. ${ }^{[111]}$ showed that increased harm avoidance is associated with abnormalities in WM microstructure in a large cohort $(n=263)$ of healthy adults. Increased harm avoidance was associated with reduced FA whereas increased mean diffusivity/radial diffusivity in specific WM tracts, such as corticolimbic pathways, was implicated in emotional processing and reappraisal. The authors speculated that the associations between WM microstructure and anxiety-related personality traits emerged early in life suggesting that both temperament and personality are closely shaped early and remain stable during the life span. ${ }^{[111]}$

There are also two voxel-based morphometry studies analyzing the association between WM abnormalities and temperamental features in healthy subjects.

In the first study, Van Schuerbeek et al. ${ }^{[112]}$ suggested that individual variations in brain morphology may be associated with temperament and character dimensions in 68 young healthy female volunteers. The authors found correlations between temperamental traits and WM volume. Specifically, a link between cooperativeness and WM volume has been observed in the medial frontal and precentral gyrus.

In the second study, Kaasinen et al. ${ }^{[113]}$ investigated whether late adulthood brain structural differences may be related to differences in temperament and character in 42 healthy aged adults.

However, no significant correlations between regional WM volumes and personality traits were reported, and only a trend of correlation between right cerebellar WM volume and self-transcendence was observed.

To our knowledge, no other studies supported the association between affective temperaments, WMHs and suicidal risk. Table 1 summarizes the most relevant evidence for the association between WM abnormalities 
Table I: Most relevant studies about the association between WM abnormalities and affective temperaments in patients with MDD and suicidal behavior

\begin{tabular}{|c|c|c|c|c|c|}
\hline Authors & $\begin{array}{l}\text { Study } \\
\text { design }\end{array}$ & Sample & Main results & Limitations & Conclusion \\
\hline $\begin{array}{l}\text { Picerni } \\
\text { et } a \text { al. }^{108]}\end{array}$ & $\begin{array}{l}\text { Cross- } \\
\text { sectional }\end{array}$ & $\begin{array}{l}100 \\
\text { healthy } \\
\text { individuals }\end{array}$ & $\begin{array}{l}\text { NS scores as assessed by } \mathrm{TCl} \\
\text { were associated positively with } \\
\text { cerebellar gray matter volumes } \\
\text { and FA, and negatively with } \\
\text { gray matter mean diffusivity. } \\
\text { Harm Avoidance, Reward } \\
\text { Dependence or Persistence } \\
\text { scores were not associated } \\
\text { with cerebellar structural } \\
\text { measures }\end{array}$ & $\begin{array}{l}\text { The study has been conducted on } \\
\text { healthy individuals. The possible causal } \\
\text { link between cerebellar structures and } \\
\text { novelty-related behaviors has not been } \\
\text { investigated. The cross-sectional nature } \\
\text { of this study should also be considered a } \\
\text { further additional limitation }\end{array}$ & $\begin{array}{l}\text { The cerebellum may } \\
\text { be a critical structure } \\
\text { implicated in novelty } \\
\text { related behaviors }\end{array}$ \\
\hline $\begin{array}{l}\text { Laricchiuta } \\
\text { et al. }{ }^{[109]}\end{array}$ & $\begin{array}{l}\text { Cross- } \\
\text { sectional }\end{array}$ & $\begin{array}{l}125 \\
\text { healthy } \\
\text { adults }\end{array}$ & $\begin{array}{l}\text { Increased bilateral caudate } \\
\text { and pallidum volumes have } \\
\text { been associated with higher NS } \\
\text { scores together with increased } \\
\text { MD in the bilateral putamen } \\
\text { associated with higher HA } \\
\text { scores as assessed by TCl. The } \\
\text { biological variance associated } \\
\text { with NS or HA personality } \\
\text { phenotype may be at least } \\
\text { partially explained by macro/ } \\
\text { microstructural variations in the } \\
\text { basal ganglia regions }\end{array}$ & $\begin{array}{l}\text { The study has been conducted on healthy } \\
\text { subjects. Finally, the cross-sectional nature } \\
\text { of this study should be considered a further } \\
\text { additional limitation }\end{array}$ & $\begin{array}{l}\text { Subjects with a } \\
\text { micro-structure } \\
\text { of putamen } \\
\text { characterized by } \\
\text { higher MD values } \\
\text { may be considered } \\
\text { more vulnerable } \\
\text { in experiencing } \\
\text { negative emotional } \\
\text { states, withdrawal, } \\
\text { and inhibition }\end{array}$ \\
\hline $\begin{array}{l}\text { Bjørnebekk } \\
\text { et al. } .^{[110]}\end{array}$ & $\begin{array}{l}\text { Cross- } \\
\text { sectional }\end{array}$ & $\begin{array}{l}263 \\
\text { healthy } \\
\text { adults }\end{array}$ & $\begin{array}{l}\text { Increased RD was associated } \\
\text { with decreased FA in anterior } \\
\text { regions including frontostriatal } \\
\text { and frontolimbic circuits. } \\
\text { Higher RD was associated } \\
\text { with decreased microstructural } \\
\text { integrity of the brain WM as } \\
\text { demonstrated by negative } \\
\text { associations between RD and } \\
\text { FA. NS and DTI indices were } \\
\text { not associated }\end{array}$ & $\begin{array}{l}\text { The study has been conducted on healthy } \\
\text { individuals. Altered reward processing } \\
\text { should be assessed in patients with major } \\
\text { neuropsychiatric disorders. Finally, the } \\
\text { cross-sectional nature of this study should } \\
\text { be considered a further additional limitation }\end{array}$ & $\begin{array}{l}\text { WM microstructure } \\
\text { frontostriatal and } \\
\text { frontolimbic circuits } \\
\text { may account for } \\
\text { variability in RD }\end{array}$ \\
\hline $\begin{array}{l}\text { Weber } \\
\text { et al. }{ }^{[104]}\end{array}$ & $\begin{array}{l}\text { 2-year } \\
\text { follow-up }\end{array}$ & $\begin{array}{l}28 \text { EOD } \\
\text { elderly } \\
\text { patients } \\
\text { and } 48 \\
\text { HP }\end{array}$ & $\begin{array}{l}\text { Increased Neuroticism } \\
\text { factor, Anxiety facet scores, } \\
\text { decreased Warmth and Positive } \\
\text { Emotions facet scores have } \\
\text { been observed at baseline } \\
\text { but reached the level of HP } \\
\text { at follow-up. Conversely, } \\
\text { significantly higher depression } \\
\text { facet scores were found in } \\
\text { EOD patients than HP at both } \\
\text { baseline and after } 2 \text { years } \\
\text { independently of depressive } \\
\text { relapse }\end{array}$ & $\begin{array}{l}\text { The study was limited by the loss of } 24 \% \\
\text { of the participants at follow-up and the } \\
\text { reduced sample size. The number of } \\
\text { relapses between baseline and follow-up } \\
\text { time points, or separate comparisons } \\
\text { of recurrent vs. single episode EOD } \\
\text { cases have not been considered. Finally, } \\
\text { the study did not provide an additional } \\
\text { comparison group of patients with LOD }\end{array}$ & $\begin{array}{l}\text { The long-term } \\
\text { evolution of } \\
\text { MDD may be } \\
\text { characterized by } \\
\text { the trait like marker } \\
\text { depression-related } \\
\text { personality facet }\end{array}$ \\
\hline $\begin{array}{l}\text { Westlye } \\
\text { et al. }{ }^{[111]}\end{array}$ & $\begin{array}{l}\text { Cross- } \\
\text { sectional }\end{array}$ & $\begin{array}{l}263 \\
\text { healthy } \\
\text { adults }\end{array}$ & $\begin{array}{l}\text { Increased } \mathrm{HA} \text { has been } \\
\text { associated with reduced FA and } \\
\text { increased MD and RD in WM } \\
\text { corticolimbic tracts }\end{array}$ & $\begin{array}{l}\text { The study has been conducted on healthy } \\
\text { subjects. Alterations in axonal density and } \\
\text { membranes together with architecture of } \\
\text { the insulating myelin sheaths have been } \\
\text { proposed as candidate mechanisms } \\
\text { underlying HA although histological } \\
\text { data were not available. Finally, the } \\
\text { cross-sectional nature of this study should } \\
\text { be considered a further additional limitation }\end{array}$ & $\begin{array}{l}\text { Structural } \\
\text { corticolimbic } \\
\text { connectivity } \\
\text { may mediate } \\
\text { anxiety-related } \\
\text { aspects of } \\
\text { personality. } \\
\text { Reduced WM } \\
\text { integrity may reflect } \\
\text { higher susceptibility } \\
\text { to psychiatric } \\
\text { disease }\end{array}$ \\
\hline $\begin{array}{l}\text { Van } \\
\text { Schuerbeek } \\
\text { et al } \text {. }^{[112]}\end{array}$ & $\begin{array}{l}\text { Cross- } \\
\text { sectional }\end{array}$ & $\begin{array}{l}68 \text { female } \\
\text { volunteers }\end{array}$ & $\begin{array}{l}\text { A correlation between } \\
\text { temperamental traits as } \\
\text { assessed by } \mathrm{TCl} \text { and WM } \\
\text { volume has been reported. } \\
\text { Specifically, a link between } \\
\text { cooperativeness and WM } \\
\text { volume of the medial frontal } \\
\text { and precentral gyrus has been } \\
\text { found }\end{array}$ & $\begin{array}{l}\text { The study has been conducted on healthy } \\
\text { individuals. DTI techniques were not used. } \\
\text { Environmental factors such as learning } \\
\text { and training that may be influenced by } \\
\text { personality have been not controlled. } \\
\text { Finally, the cross-sectional nature of this } \\
\text { study should be considered a further } \\
\text { additional limitation }\end{array}$ & $\begin{array}{l}\text { Individual variations } \\
\text { in brain morphology } \\
\text { may be associated } \\
\text { with temperament } \\
\text { and character } \\
\text { dimensions }\end{array}$ \\
\hline
\end{tabular}




\begin{tabular}{|c|c|c|c|c|c|}
\hline Authors & $\begin{array}{l}\text { Study } \\
\text { design }\end{array}$ & Sample & Main results & Limitations & Conclusion \\
\hline $\begin{array}{l}\text { Serafini } \\
\text { et al. }{ }^{[106]}\end{array}$ & $\begin{array}{l}\text { Cross- } \\
\text { sectional }\end{array}$ & $\begin{array}{l}247 \\
\text { subjects } \\
\text { with major } \\
\text { affective } \\
\text { disorders }\end{array}$ & $\begin{array}{l}48 \% \text { of patients had } \\
\text { periventricular WMHs and } 39 \% \\
\text { had deep WMHs. Patients with } \\
\text { higher dysthymia and lower } \\
\text { hyperthymia were more likely } \\
\text { to have hopelessness, more } \\
\text { WMHs, and more recent suicide } \\
\text { attempts when compared with } \\
\text { patients with higher hyperthymia } \\
\text { and lower dysthymia }\end{array}$ & $\begin{array}{l}\text { The small sample size did not allow the } \\
\text { generalization of the present findings. } \\
\text { The association between the lethality/ } \\
\text { number of suicide attempts and the } \\
\text { presence/severity of hyperintensities } \\
\text { has not been explored. The cognitive } \\
\text { effects of medications were not taken into } \\
\text { consideration and represented a limitation. } \\
\text { Finally, the cross-sectional nature of this } \\
\text { study should be considered a further } \\
\text { additional limitation }\end{array}$ & $\begin{array}{l}\text { Differences among } \\
\text { temperamental } \\
\text { groups measured } \\
\text { by the TEMPS-A } \\
\text { are associated } \\
\text { with differences } \\
\text { in MRIs. Different } \\
\text { temperamental } \\
\text { profiles are associated } \\
\text { with differences in the } \\
\text { subcortical structures } \\
\text { of the brain }\end{array}$ \\
\hline $\begin{array}{l}\text { Weber } \\
\text { et al. } .^{[105]}\end{array}$ & $\begin{array}{l}\text { Cross- } \\
\text { sectional }\end{array}$ & $\begin{array}{l}38 \text { elderly } \\
\text { remitted } \\
\text { patients } \\
\text { with EOD } \\
\text { and } 62 \\
\text { HP }\end{array}$ & $\begin{array}{l}\text { No significant group } \\
\text { differences were found in } \\
\text { WMH rates between EOD and } \\
\text { HP. Conversely, EOD was } \\
\text { associated with significant } \\
\text { increase of Neuroticism and } \\
\text { decrease of Extraversion } \\
\text { facet scores as assessed } \\
\text { by Five-Factor personality } \\
\text { dimensions }\end{array}$ & $\begin{array}{l}\text { Only EOD patients without psychiatric } \\
\text { and physical comorbidities have been } \\
\text { selected. The study was limited by its } \\
\text { cross-sectional nature }\end{array}$ & $\begin{array}{l}\text { Old EOD patients } \\
\text { without major } \\
\text { psychiatric remained } \\
\text { stable and free from } \\
\text { cognitive impairment } \\
\text { and structural/ } \\
\text { vascular alterations }\end{array}$ \\
\hline $\begin{array}{l}\text { Kaasinen } \\
\text { et al. } \text {. }^{113]}\end{array}$ & $\begin{array}{l}\text { Cross- } \\
\text { sectional }\end{array}$ & $\begin{array}{l}42 \text { healthy } \\
\text { aged } \\
\text { adults }\end{array}$ & $\begin{array}{l}\text { A positive association has been } \\
\text { observed between GM volume of } \\
\text { the temporal, parietal, and frontal } \\
\text { cortices, and self-transcendence, } \\
\text { a personality trait reflecting } \\
\text { mature creativity and spiritualism }\end{array}$ & $\begin{array}{l}\text { The study has been conducted on } \\
\text { healthy subjects. The correlation between } \\
\text { cooperativeness and CSF was significant } \\
\text { only after correction for age and gender. } \\
\text { Moreover, it was possible that the relatively } \\
\text { small differences of cooperativeness } \\
\text { scores in healthy subjects have little impact } \\
\text { on behavior. Finally, the cross-sectional } \\
\text { nature of this study should be considered a } \\
\text { further additional limitation }\end{array}$ & $\begin{array}{l}\text { High self- } \\
\text { transcendence, } \\
\text { which has adaptive } \\
\text { advantages in the } \\
\text { later part of life, } \\
\text { is associated with } \\
\text { relatively greater } \\
\text { temporal cortical GM } \\
\text { volumes }\end{array}$ \\
\hline
\end{tabular}

CSF: cerebrospinal fluid; EOD: early-onset depression; FA: fractional anisotropy; GM: grey matter; HA: harm avoidance; HP: healthy participants; LOD: late-onset depression; MD: mean diffusivity; NS: novelty seeking; RD: reward dependence; TCI: temperament and character inventory; TEMPS-A: temperament evaluation of memphis; Pisa: Paris and San Diego-auto-questionnaire; WM: white matter; WMHs: white matter hyperintensities

and affective temperaments in patients with MDD and suicidal behavior.

\section{CLINICALIMPLICATIONS AND MAIN LIMITATIONS}

According to the selected findings of the present review derived by MRI studies, WMHs have been commonly reported and associated with a poor outcome and increased suicidality in patients with MDD. This has been independently confirmed by DTI studies showing a robust association between WM microstructural abnormalities, MDD, and suicidal behavior. Neuroimaging techniques have also provided interesting results to test the association between temperaments, personality profiles and WM microstructure abnormalities [Table 1].

Based on our results, the presence of microvascular brain abnormalities and specific affective temperaments such as dysthymic subtype may exert a combined negative role in patients with MDD worsening outcome and triggering suicidality. The presence of WM abnormalities together with a dysthymic temperamental profile may be used for grouping subjects with MDD and this may potentially help clinicians in optimizing treatment strategies.
DTI techniques are undoubtedly able to more deeply investigate the nature of abnormalities in WM integrity among patients with MDD. According to DTI evidence, WM abnormalities have been re-conceptualized as microstructural damage related to vascular processes that affect brain connectivity. ${ }^{[111]}$

Atherosclerotic or ischemic lesions, micro infarcts, ${ }^{[114,115]}$ demyelination, ${ }^{[5]}$ cerebral edema, ${ }^{[16]}$ astrocyte proliferation and deposition of brain toxic material $s^{[5]}$ have been commonly proposed as the underlying mechanisms involved in the development of WM alterations. These brain lesions can be identified using both MRI and DTI techniques, with the latter allowing the detection of location, orientation and anisotropy of brain WM tracts.

Untill a few years ago, white matter has been supposed to be a passive tissue, but according to recent evidence it has been suggested as actively implicated in major psychiatric conditions and brain functioning. Notably, the timing of WM growth and degree of completion may influence important human abilities such as affect learning, memory, and self-control ability.

Understanding the nature and origin of WM alterations in MDD is of paramount importance as they may 
be associated with a poor clinical course, increased disability, negative psychosocial impairment ${ }^{[117]}$ and response to treatment as well as functional decline. ${ }^{[118-121]}$

Recently, WM abnormalities detected using DTI have also contributed to clarify the pathophysiological mechanisms underlying suicidal behavior. Olvet et al..$^{[15]}$ conducted a DTI study on 13 suicide attempters with MDD, 39 unipolar depressed non-attempters, and 46 healthy participants and found that low FA in the dorsomedial prefrontal cortex (DMPFC) was associated with a suicide attempt history. Similar results have also been reported by Jollant et al. ${ }^{[122]}$ in a functional MRI study. They found reduced activation in the DMPFC of remitted MDD suicide attempters compared with subjects who did not attempt suicide.

Lopez-Larson et al. ${ }^{[16]}$ reported that nineteen veterans with mild traumatic brain injury and a history of suicidal behavior had greater FA measures in bilateral thalamic radiations compared to forty veterans with mild traumatic brain injury without suicidal behavior and healthy controls. Among veterans with mild traumatic brain injury and a history of suicidal behavior, right thalamic volumes negatively correlated with anxiety symptoms whereas total mean FA values for the right anterior thalamic radiations positively correlated with impulsivity.

Furthermore, a positive correlation between current suicidal ideation and FA was reported in the cingulate ${ }^{[17]}$ of 15 male veterans with traumatic brain injury and 17 matched healthy controls. Interestingly, the authors suggested the existence of a neurobiological vulnerability to suicidal risk related to WM microstructure.

Another DTI study ${ }^{[123]}$ investigated the effect of past suicide attempts in 63 patients with MDD (23 with and 40 without a history of suicide attempts) and 46 healthy controls. The authors reported that those with a history of suicide attempts had greater abnormalities in the left orbitofrontal cortex and thalamus when compared with those without suicide attempts whereas reduced fiber projections through the ALIC to the left medial frontal cortex, orbitofrontal cortex and thalamus were found in both groups of patients [Table 2].

Further potential support (external validation) to the association between microstructural WM abnormalities and suicidality in patients with MDD may be also provided by the earlier age at illness onset in some MDD patients with higher WM abnormalities as well as the very well replicated finding of early-onset suicidality in patients with mood disorders. ${ }^{[2]}$
Many years ago, Hopkinson ${ }^{[124]}$ reported that the risk of depression in the first-degree relatives of depressed subjects was greater $(20 \%)$ in the EOD group compared with the LOD group (8.3\%) over 50 years of age. Similar findings have been later reported by Schultz ${ }^{[125]}$ and Post $^{[126]}$ supporting the hypothesis that genetic factors may show greater effects in EOD compared to late-onset depression. More recently, these findings have been replicated by Takahashi et al. ${ }^{[5]}$ who suggested that early-onset type may be more closely associated with nonvascular factors such as genetic factors.

Komaki et al. ${ }^{[127]}$ also reported that WM lesions were significantly correlated with age at initial onset of depression (45.8 years) in 123 MDD subjects. The authors also found that the rate of suicide in those patients with lacunar infarction $17.9 \%$ of the total sample) was significantly higher than that in subjects with no abnormal findings or those with WMHs but no lacunar infarction, suggesting that the prognosis was worse in those with lacunar infarction relative to the other two groups. Unfortunately, not all studies found a relationship between subcortical hyperintensities and age at onset in patients with mood disorders. ${ }^{[128-130]}$

There may be many possible causes underlying WM lesions that can occur over time and may be quite progressive or rather static. WM lesions may be also detected in younger adults without typical cardio- and cerebro-vascular risk factors and are occasionally associated with inflammatory/demyelinating diseases. ${ }^{[131]}$ In this case, it has been suggested that they are presumably genetically determined. Recently, Sprooten et al. ${ }^{[132]}$ suggested that WM integrity was a reliable endophenotype for bipolar disorder with important behavioral associations linked to the etiology of this condition. Specifically, they reported widespread WM integrity reductions in unaffected relatives of bipolar patients and cyclothymic temperament. Although the authors did not investigate patients with a history of suicide and they did not report implications related to suicide risk in the analyzed cohort, their study suggested that impaired WM integrity might be a potential mechanism of genetic predisposition for bipolar disorder. Reduced fronto-temporal and fronto-thalamic WM integrity may represent a structural substrate of mood instability in both healthy control subjects and unaffected relatives at high genetic risk for bipolar disorder. Interestingly, cyclothymia resulted negatively associated with WM integrity of the internal capsules bilaterally and left temporal lobe in both high-risk subjects and controls. The authors supported the assumption that WM abnormalities might have behavioral associations related to the symptomatology of the illness. 
Table 2: Most relevant DTI studies about alterations in WM integrity and suicidal behavior

\begin{tabular}{|c|c|c|c|c|c|}
\hline Authors & $\begin{array}{l}\text { Study } \\
\text { design }\end{array}$ & Sample & Main results & Limitations & Conclusion \\
\hline Olvet et al. ${ }^{[15]}$ & $\begin{array}{l}\text { Cross- } \\
\text { sectional }\end{array}$ & $\begin{array}{l}13 \text { suicide } \\
\text { attempters } \\
\text { with MDD, } 39 \\
\text { non-attempters } \\
\text { with MDD, and } \\
46 \mathrm{HP}\end{array}$ & $\begin{array}{l}\text { Suicide attempters reported } \\
\text { lower FA relative to MDD } \\
\text { non-attempters and HP in the } \\
\text { DLPFC. A significant cluster } \\
\text { within the right DLPFC has } \\
\text { been confirmed according to } \\
\text { uncorrected TBSS findings. } \\
\text { No differences in ADC when } \\
\text { comparing the three groups } \\
\text { using ROI or TBSS methods } \\
\text { were found }\end{array}$ & $\begin{array}{l}\text { The small sample size did not } \\
\text { allow the generalization of findings. } \\
\text { HP group was younger than the } \\
\text { non-attempter group. The most } \\
\text { recent suicide attempt ranged } \\
\text { from } 19 \text { days to } 39 \text { years before } \\
\text { the DTI scan. The possible effect } \\
\text { of medications (antidepressants) } \\
\text { should be not excluded. Finally, the } \\
\text { cross-sectional nature of this study } \\
\text { should be considered a further } \\
\text { additional limitation }\end{array}$ & $\begin{array}{l}\text { WM abnormalities } \\
\text { may contribute to } \\
\text { functional deficits } \\
\text { associated with } \\
\text { suicidal behavior }\end{array}$ \\
\hline $\begin{array}{l}\text { Lopez- } \\
\text { Larson } \\
\text { et al. } .^{[16]}\end{array}$ & $\begin{array}{l}\text { Cross- } \\
\text { sectional }\end{array}$ & $\begin{array}{l}40 \text { veterans with } \\
\text { mild TBI and no } \\
\mathrm{SB}, 19 \text { veterans } \\
\text { with mild TBI } \\
\text { and a history of } \\
\mathrm{SB} \text {, and } 15 \mathrm{HP}\end{array}$ & $\begin{array}{l}\text { Left and right thalamic } \\
\text { volumes were reported as } \\
\text { significantly increased in } \\
\text { those with TBI and a history } \\
\text { of SB compared to the HP, } \\
\text { TBI and a history of SB, and } \\
\text { the combined group. Veterans } \\
\text { with TBI and a history of SB } \\
\text { had increased FA bilaterally } \\
\text { compared to the HP, HP and } \\
\text { TBI with a history of SB group, } \\
\text { and the TBI with a history of } \\
\text { SB only group. Significant } \\
\text { positive associations were } \\
\text { found for bilateral ATR and } \\
\text { BIS in those with TBI and a } \\
\text { history of SB }\end{array}$ & $\begin{array}{l}\text { The small sample size did not allow } \\
\text { the generalization of findings. Of } \\
\text { note, the study included only male } \\
\text { subjects. The cross-sectional nature } \\
\text { of this study should be considered a } \\
\text { further additional limitation }\end{array}$ & $\begin{array}{l}\text { Thalamic } \\
\text { enlargement and } \\
\text { increased FA in } \\
\text { subjects with TBI } \\
\text { and a history of } \\
\text { SB suggested that } \\
\text { this region may } \\
\text { be considered a } \\
\text { potential biomarker of } \\
\text { suicidal behavior }\end{array}$ \\
\hline $\begin{array}{l}\text { Yurgelun- } \\
\text { Todd et al. }{ }^{[17]}\end{array}$ & $\begin{array}{l}\text { Cross- } \\
\text { sectional }\end{array}$ & $\begin{array}{l}\text { Fifteen male } \\
\text { veterans with } \\
\text { TBI and } 17 \\
\text { matched HP }\end{array}$ & $\begin{array}{l}\text { A significant reduction in FA } \\
\text { values of the left cingulum and } \\
\text { left/total genu was observed } \\
\text { in the TBI group compared to } \\
\text { HP. Subjects with TBI were } \\
\text { more likely to have higher } \\
\text { impulsivity than HP. A positive } \\
\text { correlation between current } \\
\text { suicidal ideation, impulsivity, } \\
\text { and total and right cingulum } \\
\text { FA has been observed }\end{array}$ & $\begin{array}{l}\text { The small sample size did not allow } \\
\text { the generalization of findings. The } \\
\text { cross-sectional nature of this study } \\
\text { should be considered a further } \\
\text { additional limitation }\end{array}$ & $\begin{array}{l}\text { A potential } \\
\text { neurobiological } \\
\text { vulnerability to } \\
\text { suicidal risk may } \\
\text { be mediated by the } \\
\text { significant reduction } \\
\text { in FA of frontal WM } \\
\text { tracts in veterans with } \\
\text { mild TBI associated } \\
\text { with both impulsivity } \\
\text { and suicidality }\end{array}$ \\
\hline Jia et al. ${ }^{[123]}$ & $\begin{array}{l}\text { Cross- } \\
\text { sectional }\end{array}$ & $\begin{array}{l}63 \text { patients with } \\
\text { MDD ( } 23 \text { with } \\
\text { and } 40 \text { without a } \\
\text { history of suicide } \\
\text { attempts) and } \\
46 \mathrm{HP}\end{array}$ & $\begin{array}{l}\text { Both groups of depressed } \\
\text { patients had reduced fiber } \\
\text { projections through the } \\
\text { ALIC to the left medial } \\
\text { frontal cortex, orbitofrontal } \\
\text { cortex, and thalamus. Those } \\
\text { with a history of suicide } \\
\text { attempts were more likely } \\
\text { to have alterations in the } \\
\text { left orbitofrontal cortex and } \\
\text { thalamus than those without a } \\
\text { history of suicide attempts }\end{array}$ & $\begin{array}{l}\text { The study may be limited in terms of } \\
\text { power to examine variability in brain } \\
\text { anatomy concerning any specific } \\
\text { method of suicide attempts, specific } \\
\text { previous treatments, or number of } \\
\text { previous attempts and depressive } \\
\text { episodes. Personality has not } \\
\text { been evaluated. According to DTI } \\
\text { analyses, the ability of the present } \\
\text { study to distinguish the directionality } \\
\text { of altered fiber tracts is very } \\
\text { limited. Furthermore, the degree to } \\
\text { which alterations in the ALIC are } \\
\text { restricted to the left hemisphere } \\
\text { needs to be evaluated. Finally, the } \\
\text { present findings may be not able to } \\
\text { establish the direction of causality }\end{array}$ & $\begin{array}{l}\text { WM alterations of } \\
\text { frontothalamic circuits } \\
\text { may contribute to } \\
\text { cognitive/affective } \\
\text { deficits increasing } \\
\text { vulnerability for } \\
\text { suicidal behavior in } \\
\text { depressed patients }\end{array}$ \\
\hline
\end{tabular}

ADC: apparent diffusion coefficient; ALIC: left anterior limb of the internal capsule; ATR: anterior thalamic radiations; BD: bipolar disorder; BIS: Barratt Impulsiveness Scale; DTI: diffusion tensor imaging; DLPFC: dorsomedial prefrontal cortex; FA: fractional anisotropy; HP: healthy participants; MDD: major depressive disorder; ROI: region of interest; SB: suicidal behavior; TBI: traumatic brain injury; TBSS: tract-based spatial statistics; WM: white matter

Some limitations potentially contributing to the lack of consistency of the present findings need to be addressed. First, WMHs in patients with MDD should be interpreted as an extreme consequence of underlying microstructural dysfunctions affecting brain connectivity. Second, most studies did not assess patients for the presence and severity of possible confounding variables (such as vascular risk factors) together with history of substance abuse/ dependence and prior mood episodesas as well as the burden of comorbidities. Another important caveat regards the use of psychotropic medications potentially influencing both the presence and severity of WM lesions. 


\section{CONCLUSION}

White matter abnormalities may be proposed as biological markers of poor outcome in patients with MDD also triggering suicidal behavior. The presence of WMHs may be used for grouping and closely monitoring those patients with more severe illness impairments requiring more targeted interventions. However, further prospective studies are needed to more deeply investigate differential outcome trajectories as well as to develop tailored treatment strategies in patients with MDD. This field is rapidly expanding, and we are only at the beginning of this interesting journey. A better understanding of the biological processes involved in the progression of WM alterations is undoubtedly necessary.

\section{Financial support and sponsorship}

Nil.

\section{Conflicts of interest}

There are no conflicts of interest.

\section{REFERENCES}

1. Cho DY, Lee WY, Chen CC. Limbic leukotomy for intractable major affective disorders: a 7-year follow-up study using nine comprehensive psychiatric test evaluations. J Clin Neurosci 2008;15:138-42.

2. Rihmer Z. Suicide risk in mood disorders. Curr Opin Psychiatry 2007;20:17-22.

3. Hawton K, van Heeringen K. Suicide. Lancet 2009;373:1372-81.

4. Thomas AJ, Perry R, Barber R, Kalaria RN, O'Brien JT. Pathologies and pathological mechanisms for white matter hyperintensities in depression. Ann N Y Acad Sci 2002;977:333-9.

5. Thomas AJ, O'Brien JT, Davis S, Ballard C, Barber R, Kalaria RN, Perry RH. Ischemic basis for deep white matter hyperintensities in major depression: a neuropathological study. Arch Gen Psychiatry 2002;59:785-92.

6. Ehrlich S, Noam GG, Lyoo IK, Kwon BJ, Clark MA, Renshaw PF. Subanalysis of the location of white matter hyperintensities and their association with suicidality in children and youth. Ann N Y Acad Sci 2003;1008:265-8.

7. Ehrlich S, Noam GG, Lyoo IK, Kwon BJ, Clark MA, Renshaw PF. White matter hyperintensities and their associations with suicidality in psychiatrically hospitalized children and adolescents. J Am Acad Child Adolesc Psychiatry 2004;43:770-6.

8. Ehrlich S, Breeze JL, Hesdorffer DC, Noam GG, Hong X, Alban RL, Davis SE, Renshaw PF. White matter hyperintensities and their association with suicidality in depressed young adults. J Affect Disord 2005;86:281-7.

9. Pompili M, Ehrlich S, De Pisa E, Mann JJ, Innamorati M, Cittadini A, Montagna B, Iliceto P, Romano A, Amore M, Tatarelli R, Girardi P. White matter hyperintensities and their associations with suicidality in patients with major affective disorders. Eur Arch Psychiatry Clin Neurosci 2007;257:494-9.

10. Zanetti MV, Schaufelberger MS, de Castro CC, Menezes PR, Scazufca M, McGuire PK, Murray RM, Busatto GF. White-matter hyperintensities in first-episode psychosis. $\mathrm{Br} J$ Psychiatry 2008;193:25-30.

11. Qin J, Wei M, Liu H, Chen J, Yan R, Hua L, Zhao K, Yao Z, Lu Q. Abnormal hubs of white matter networks in the frontal-parieto circuit contribute to depression discrimination via pattern classification. Magn Reson Imaging 2014;32:1314-20.

12. Korgaonkar MS, Fornito A, Williams LM, Grieve SM. Abnormal structural networks characterize major depressive disorder: a connectome analysis. Biol Psychiatry 2014;76:567-74.

13. Lai $\mathrm{CH}, \mathrm{Wu} \mathrm{YT}$. Alterations in white matter micro-integrity of the superior longitudinal fasciculus and anterior thalamic radiation of young adult patients with depression. Psychol Med 2014;44:2825-32.

14. Song YJ, Korgaonkar MS, Armstrong LV, Eagles S, Williams LM, Grieve SM. Tractography of the brainstem in major depressive disorder using diffusion tensor imaging. PLoS One 2014;9:e84825

15. Olvet DM, Peruzzo D, Thapa-Chhetry B, Sublette ME, Sullivan GM, Oquendo MA, Mann JJ, Parsey RV. A diffusion tensor imaging study of suicide attempters. J Psychiatr Res 2014;51:60-7.

16. Lopez-Larson M, King JB, McGlade E, Bueler E, Stoeckel A, Epstein DJ, Yurgelun-Todd D. Enlarged thalamic volumes and increased fractional anisotropy in the thalamic radiations in veterans with suicide behaviors. Front Psychiatry 2013;4:83.

17. Yurgelun-Todd DA, Bueler CE, McGlade EC, Churchwell JC, Brenner LA, Lopez-Larson MP. Neuroimaging correlates of traumatic brain injury and suicidal behavior. J Head Trauma Rehabil 2011;26:276-89.

18. Jia Z, Wang Y, Huang X, Kuang W, Wu Q, Lui S, Sweeney JA, Gong Q. Impaired frontothalamic circuitry in suicidal patients with depression revealed by diffusion tensor imaging at 3.0 T. JPsychiatry Neurosci 2014;39:170-7.

19. LeWinn KZ, Connolly CG, Wu J, Drahos M, Hoeft F, Ho TC, Simmons AN, Yang TT. White matter correlates of adolescent depression: structural evidence for frontolimbic disconnectivity. J Am Acad Child Adolesc Psychiatry 2014;53:899-909, 909.e1-7.

20. Bessette KL, Nave AM, Caprihan A, Stevens MC. White matter abnormalities in adolescents with major depressive disorder. Brain Imaging Behav 2014;8:531-41.

21. de Kwaasteniet B, Ruhe E, Caan M, Rive M, Olabarriaga S, Groefsema M, Heesink L, van Wingen G, Denys D. Relation between structural and functional connectivity in major depressive disorder. Biol Psychiatry 2013;74:40-7.

22. Tha KK, Terae S, Nakagawa S, Inoue T, Kitagawa N, Kako Y, Nakato Y, Akter Popy K, Fujima N, Zaitsu Y, Yoshida D, Ito YM, Miyamoto T, Koyama T, Shirato $\mathrm{H}$. Impaired integrity of the brain parenchyma in non-geriatric patients with major depressive disorder revealed by diffusion tensor imaging. Psychiatry Res 2013;212:208-15.

23. Macmaster FP, Carrey N, Marie Langevin L. Corpus callosal morphology in early onset adolescent depression. J Affect Disord 2013;145:256-9.

24. Henderson SE, Johnson AR, Vallejo AI, Katz L, Wong E, Gabbay V. A preliminary study of white matter in adolescent depression: relationships with illness severity, anhedonia, and irritability. Front Psychiatry 2013;4:152.

25. Bracht T, Horn H, Strik W, Federspiel A, Schnell S, Höfle O, Stegmayer K, Wiest R, Dierks T, Muller TJ, Walther S. White matter microstructure alterations of the medial forebrain bundle in melancholic depression. J Affect Disord 2014;155:186-93.

26. Bracht T, Federspiel A, Schnell S, Horn H, Höfle O, Wiest R, Dierks T, Strik W, Muller TJ, Walther S. Cortico-cortical white matter motor pathway microstructure is related to psychomotor retardation in major depressive disorder. PLoS One 2012;7:e52238.

27. Lyden H, Espinoza RT, Pirnia T, Clark K, Joshi SH, Leaver AM, Woods RP, Narr KL. Electroconvulsive therapy mediates neuroplasticity of white matter microstructure in major depression. Transl Psychiatry 2014;4:e380.

28. Hoogenboom WS, Perlis RH, Smoller JW, Zeng-Treitler Q, Gainer VS, Murphy SN, Churchill SE, Kohane IS, Shenton ME, Iosifescu DV. Limbic system white matter microstructure and long-term treatment outcome in major depressive disorder: a diffusion tensor imaging study using legacy data. World J Biol Psychiatry 2014;15:122-34.

29. Korgaonkar MS, Williams LM, Song YJ, Usherwood T, Grieve SM. Diffusion tensor imaging predictors of treatment outcomes in major depressive disorder. Br J Psychiatry 2014;205:321-8.

30. Choi KS, Holtzheimer PE, Franco AR, Kelley ME, Dunlop BW, 
Hu XP, Mayberg HS. Reconciling variable findings of white matter integrity in major depressive disorder. Neuropsychopharmacology 2014;39:1332-9.

31. Hayakawa YK, Sasaki H, Takao H, Mori H, Hayashi N, Kunimatsu A, Aoki S, Ohtomo K. Structural brain abnormalities in women with subclinical depression, as revealed by voxel-based morphometry and diffusion tensor imaging. $J$ Affect Disord 2013;144:263-8.

32. Osoba A, Hänggi J, Li M, Horn DI, Metzger C, Eckert U, Kaufmann J, Zierhut K, Steiner J, Schiltz K, Heinze HJ, Bogerts B, Walter M. Disease severity is correlated to tract specific changes of fractional anisotropy in MD and CM thalamus - a DTI study in major depressive disorder. J Affect Disord 2013;149:116-28.

33. Wang T, Huang X, Huang P, Li D, Lv F, Zhang Y, Zhang Y, Zhou L, Yang D, Xie P. Early-stage psychotherapy produces elevated frontal white matter integrity in adult major depressive disorder. PLoS One 2013;8:e63081.

34. Taylor WD, Payne ME, Krishnan KR, Wagner HR, Provenzale JM, Steffens DC, MacFall JR. Evidence of white matter tract disruption in MRI hyperintensities. Biol Psychiatry 2001;50:179-83.

35. Soares JC, Mann JJ. The anatomy of mood disorders - review of structural neuroimaging studies. Biol Psychiatry 1997;41:86-106.

36. Akiskal HS, Akiskal KK. TEMPS: temperament evaluation of Memphis, Pisa, Paris and San Diego. J Affect Disord 2005;85:1-2.

37. Rihmer Z, Akiskal KK, Rihmer A, Akiskal HS. Current research on affective temperaments. Curr Opin Psychiatry 2010;23:12-8.

38. Oedegaard KJ, Syrstad VE, Morken G, Akiskal HS, Fasmer OB. A study of age at onset and affective temperaments in a Norwegian sample of patients with mood disorders. J Affect Disord 2009; 118:229-33

39. Parker G. Modern diagnostic concepts of the affective disorders. Acta Psychiatr Scand Suppl 2003;108:24-8.

40. Akiskal HS, Mallya G. Criteria for the "soft" bipolar spectrum: treatment implications. Psychopharmacol Bull 1987;23:68-73.

41. Kamei K, Terao T, Katayama Y, Hoaki N. Affective temperaments and psychotropic adherence. J Affect Disord 2013;150:1142-7.

42. Lara DR, Pinto O, Akiskal K, Akiskal HS. Toward an integrative model of the spectrum of mood, behavioral and personality disorders based on fear and anger traits: I. Clinical implications. J Affect Disord 2006;94:67-87.

43. Sayin A, Aslan S. The relationship between mood disorders and temperament, character and personality. Turk Psikiyatri Derg 2005; 16:276-83.

44. Akdeniz F, Kesebir S, Vahip S, Gönül AS. Is there a relationship between mood disorders and affective temperaments? Turk Psikiyatri Derg 2004;15:183-90.

45. Wang L, Leonards CO, Sterzer P, Ebinger M. White matter lesions and depression: a systematic review and meta-analysis. J Psychiatr Res 2014;56:56-64.

46. Tham MW, Woon PS, Sum MY, Lee TS, Sim K. White matter abnormalities in major depression: evidence from post-mortem, neuroimaging and genetic studies. J Affect Disord 2011;132:26-36.

47. Kempton MJ, Salvador Z, Munafò MR, Geddes JR, Simmons A, Frangou S, Williams SC. Structural neuroimaging studies in major depressive disorder. Meta-analysis and comparison with bipolar disorder. Arch Gen Psychiatry 2011;68:675-90.

48. Dotson VM, Zonderman AB, Kraut MA, Resnick SM. Temporal relationships between depressive symptoms and white matter hyperintensities in older men and women. Int $J$ Geriatr Psychiatry 2013;28:66-74

49. Herrmann LL, Le Masurier M, Ebmeier KP. White matter hyperintensities in late life depression: a systematic review. J Neurol Neurosurg Psychiatry 2008;79:619-24

50. Tupler LA, Krishnan KR, McDonald WM, Dombeck CB, D'Souza S, Steffens DC. Anatomic location and laterality of MRI signal hyperintensities in late-life depression. $J$ Psychosom Res 2002;53:665-76.

51. Iidaka T, Nakajima T, Kawamoto K, Fukuda H, Suzuki Y, Maehara T, Shiraishi H. Signal hyperintensities on brain magnetic resonance imaging in elderly depressed patients. Eur Neurol 1996;36:293-9.
52. Coffey CE, Wilkinson WE, Weiner RD, Parashos IA, Djang WT, Webb MC, Figiel GS, Spritzer CE. Quantitative cerebral anatomy in depression. A controlled magnetic resonance imaging study. Arch Gen Psychiatry 1993;50:7-16.

53. Salloway S, Malloy P, Kohn R, Gillard E, Duffy J, Rogg J, Tung G, Richardson E, Thomas C, Westlake R. MRI and neuropsychological differences in early- and late-life-onset geriatric depression. Neurology 1996;46:1567-74.

54. Gunning-Dixon FM, Walton M, Cheng J, Acuna J, Klimstra S, Zimmerman ME, Brickman AM, Hoptman MJ, Young RC, Alexopoulos GS. MRI signal hyperintensities and treatment remission of geriatric depression. J Affect Disord 2010;126:395-401.

55. Takahashi K, Oshima A, Ida I, Kumano H, Yuuki N, Fukuda M, Amanuma M, Endo K, Mikuni M. Relationship between age at onset and magnetic resonance image-defined hyperintensities in mood disorders. J Psychiatr Res 2008;42:443-50.

56. Greenwald BS, Kramer-Ginsberg E, Krishnan RR, Ashtari M, Aupperle PM, Patel M. MRI signal hyperintensities in geriatric depression. Am J Psychiatry 1996;153:1212-5.

57. Kumar A, Miller D. Neuroimaging in late-life mood disorders. Clin Neurosci 1997:4:8-15.

58. Brody AL, Barsom MW, Bota RG, Saxena S. Prefrontal-subcortical and limbic circuit mediation of major depressive disorder. Semin Clin Neuropsychiatry 2001;6:102-12.

59. Sneed JR, Culang-Reinlieb ME, Brickman AM, Gunning-Dixon FM, Johnert L, Garcon E, Roose SP. MRI signal hyperintensities and failure to remit following antidepressant treatment. $J$ Affect Disord 2011;135:315-20.

60. Arnone D, McIntosh AM, Ebmeier KP, Munafò MR, Anderson IM Magnetic resonance imaging studies in unipolar depression: systematic review and meta-regression analyses. Eur Neuropsychopharmacol 2012;22:1-16.

61. Heiden A, Kettenbach J, Fischer P, Schein B, Ba-Ssalamah A, Frey R, Naderi MM, Gulesserian T, Schmid D, Trattnig S, Imhof H, Kasper S. White matter hyperintensities and chronicity of depression. J Psychiatr Res 2005;39:285-93.

62. O'Brien J, Ames D, Chiu E, Schweitzer I, Desmond P, Tress B. Severe deep white matter lesions and outcome in elderly patients with major depressive disorder: follow up study. BMJ 1998;317:982-4.

63. Hickie I, Scott E, Mitchell P, Wilhelm K, Austin MP, Bennett B. Subcortical hyperintensities on magnetic resonance imaging: clinical correlates and prognostic significance in patients with severe depression. Biol Psychiatry 1995;37:151-60.

64. Simpson S, Talbot PR, Snowden JS, Neary D. Subcortical vascular disease in elderly patients with treatment resistant depression. J Neurol Neurosurg Psychiatry 1997;62:196-7.

65. Taylor WD, Steffens DC, MacFall JR, McQuoid DR, Payne ME, Provenzale JM, Krishnan KR. White matter hyperintensity progression and late-life depression outcomes. Arch Gen Psychiatry 2003;60:1090-6

66. Hickie I, Scott E, Wilhelm K, Brodaty H. Subcortical hyperintensities on magnetic resonance imaging in patients with severe depression - $\mathrm{A}$ longitudinal evaluation. Biol Psychiatry 1997;42:367-74.

67. Lesser IM, Mena I, Boone KB, Miller BL, Mehringer CM, Wohl M. Reduction of cerebral blood flow in older depressed patients. Arch Gen Psychiatry 1994;51:677-86.

68. Kramer-Ginsberg E, Greenwald BS, Krishnan KR, Christiansen B Hu J, Ashtari M, Patel M, Pollack S. Neuropsychological functioning and MRI signal hyperintensities in geriatric depression. Am $J$ Psychiatry 1999;156:438-44.

69. Murata T, Kimura H, Omori M, Kado H, Kosaka H, Iidaka T, Itoh H, Wada Y. MRI white matter hyperintensities, (1) H-MR spectroscopy and cognitive function in geriatric depression: a comparison of early- and late-onset cases. Int J Geriatr Psychiatry 2001;16:1129-35.

70. Sheline YI, Price JL, Vaishnavi SN, Mintun MA, Barch DM Epstein AA, Wilkins CH, Snyder AZ, Couture L, Schechtman K, McKinstry RC. Regional white matter hyperintensity burden in automated segmentation distinguishes late-life depressed subjects 
from comparison subjects matched for vascular risk factors. Am $J$ Psychiatry 2008;165:524-32.

71. Serafini G, Pompili M, Innamorati M, Negro A, Fiorillo M, Lamis DA, Erbuto D, Marsibilio F, Romano A, Amore M, D'Alonzo L, Bozzao A, Girardi P, Martelletti P. White matter hyperintensities and self-reported depression in a sample of patients with chronic headache. J Headache Pain 2012;13:661-7.

72. Grangeon MC, Seixas C, Quarantini LC, Miranda-Scippa A, Pompili M, Steffens DC, Wenzel A, Lacerda AL, de Oliveira IR. White matter hyperintensities and their association with suicidality in major affective disorders: a meta-analysis of magnetic resonance imaging studies. CNS Spectr 2010;15:375-81.

73. Pompili M, Innamorati M, Mann JJ, Oquendo MA, Lester D, Del Casale A, Serafini G, Rigucci S, Romano A, Tamburello A, Manfredi G, De Pisa E, Ehrlich S, Giupponi G, Amore M, Tatarelli R, Girardi P. Periventricular white matter hyperintensities as predictors of suicide attempts in bipolar disorders and unipolar depression. Prog Neuropsychopharmacol Biol Psychiatry 2008;32:1501-7.

74. Fazekas F, Niederkorn K, Schmidt R, Offenbacher H, Horner S, Bertha G, Lechner $\mathrm{H}$. White matter signal abnormalities in normal individuals: correlation with carotid ultrasonography, cerebral blood flow measurements, and cerebrovascular risk factors. Stroke 1988;19:1285-8.

75. Alexopoulos GS, Kiosses DN, Choi SJ, Murphy CF, Lim KO. Frontal white matter microstructure and treatment response of late-life depression: a preliminary study. Am J Psychiatry 2002;159:1929-32.

76. Li L, Ma N, Li Z, Tan L, Liu J, Gong G, Shu N, He Z, Jiang T, Xu L. Prefrontal white matter abnormalities in young adult with major depressive disorder: a diffusion tensor imaging study. Brain Res 2007;1168:124-8

77. Ma N, Li L, Shu N, Liu J, Gong G, He Z, Li Z, Tan L, Stone WS, Zhang Z, Xu L, Jiang T. White matter abnormalities in first-episode, treatment-naive young adults with major depressive disorder. Am J Psychiatry 2007;164:823-6.

78. Taylor WD, MacFall JR, Payne ME, McQuoid DR, Provenzale JM, Steffens DC, Krishnan KR. Late-life depression and microstructural abnormalities in dorsolateral prefrontal cortex white matter. Am J Psychiatry 2004;161:1293-6.

79. Bae JN, MacFall JR, Krishnan KR, Payne ME, Steffens DC, Taylor WD. Dorsolateral prefrontal cortex and anterior cingulate cortex white matter alterations in late-life depression. Biol Psychiatry 2006;60:1356-63

80. Nobuhara K, Okugawa G, Sugimoto T, Minami T, Tamagaki C, Takase K, Saito Y, Sawada S, Kinoshita T. Frontal white matter anisotropy and symptom severity of late-life depression: a magnetic resonance diffusion tensor imaging study. $J$ Neurol Neurosurg Psychiatry 2006;77:120-2.

81. Zhang A, Leow A, Ajilore O, Lamar M, Yang S, Joseph J, Medina J, Zhan L, Kumar A. Quantitative tract-specific measures of uncinate and cingulum in major depression using diffusion tensor imaging. Neuropsychopharmacology 2012;37:959-67.

82. Steffens DC, Taylor WD, Denny KL, Bergman SR, Wang L. Structural integrity of the uncinate fasciculus and resting state functional connectivity of the ventral prefrontal cortex in late life depression. PLoS One 2011;6:e22697.

83. Guo WB, Liu F, Xue ZM, Gao K, Wu RR, Ma CQ, Liu ZN, Xiao CQ, Chen HF, Zhao JP. Altered white matter integrity in young adults with first-episode, treatment-naive, and treatment-responsive depression. Neurosci Lett 2012;522:139-44.

84. Aghajani M, Veer IM, van Lang ND, Meens PH, van den Bulk BG, Rombouts SA, Vermeiren RR, van der Wee NJ. Altered white-matter architecture in treatment-naive adolescents with clinical depression. Psychol Med 2013. [Epub ahead of print].

85. Cullen KR, Klimes-Dougan B, Muetzel R, Mueller BA, Camchong J, Houri A, Kurma S, Lim KO. Altered white matter microstructure in adolescents with major depression: a preliminary study. J Am Acad Child Adolesc Psychiatry 2010;49:173-83.e1.

86. Walther S, Hügli S, Höfle O, Federspiel A, Horn H, Bracht T, Wiest R, Strik W, Muller TJ. Frontal white matter integrity is related to psychomotor retardation in major depression. Neurobiol Dis 2012;47:13-9.

87. Cole J, Chaddock CA, Farmer AE, Aitchison KJ, Simmons A, McGuffin P, Fu CH. White matter abnormalities and illness severity in major depressive disorder. Br J Psychiatry 2012;201:33-9.

88. Colloby SJ, Firbank MJ, Thomas AJ, Vasudev A, Parry SW, O'Brien JT. White matter changes in late-life depression: a diffusion tensor imaging study. J Affect Disord 2011;135:216-20.

89. Korgaonkar MS, Grieve SM, Koslow SH, Gabrieli JD, Gordon E, Williams LM. Loss of white matter integrity in major depressive disorder: evidence using tract-based spatial statistical analysis of diffusion tensor imaging. Hum Brain Mapp 2011;32:2161-71.

90. Wu F, Tang Y, Xu K, Kong L, Sun W, Wang F, Kong D, Li Y, Liu Y. Whiter matter abnormalities in medication-naive subjects with a single short-duration episode of major depressive disorder. Psychiatry Res 2011;191:80-3.

91. Ouyang X, Tao HJ, Liu HH, Deng QJ, Sun ZH, Xu L, Liu ZN, Xue ZM. White matter integrity deficit in treatment-naïve adult patients with major depressive disorder. East Asian Arch Psychiatry 2011;21:5-9.

92. Zhu X, Wang X, Xiao J, Zhong M, Liao J, Yao S. Altered white matter integrity in first-episode, treatment-naive young adults with major depressive disorder: a tract-based spatial statistics study. Brain Res 2011;1369:223-9.

93. Lamar M, Charlton RA, Morris RG, Markus HS. The impact of subcortical white matter disease on mood in euthymic older adults: a diffusion tensor imaging study. Am J Geriatr Psychiatry 2010;18:634-42.

94. Zou K, Huang X, Li T, Gong Q, Li Z, Ou-yang L, Deng W, Chen Q, Li C, Ding Y, Sun X. Alterations of white matter integrity in adults with major depressive disorder: a magnetic resonance imaging study. J Psychiatry Neurosci 2008;33:525-30.

95. Alexopoulos GS, Murphy CF, Gunning-Dixon FM, Latoussakis V, Kanellopoulos D, Klimstra S, Lim KO, Hoptman MJ. Microstructural white matter abnormalities and remission of geriatric depression. Am J Psychiatry 2008;165:238-44.

96. Liao Y, Huang X, Wu Q, Yang C, Kuang W, Du M, Lui S, Yue Q, Chan RC, Kemp GJ, Gong Q. Is depression a disconnection syndrome? Meta-analysis of diffusion tensor imaging studies in patients with MDD. J Psychiatry Neurosci 2013;38:49-56.

97. Murphy ML, Frodl T. Meta-analysis of diffusion tensor imaging studies shows altered fractional anisotropy occurring in distinct brain areas in association with depression. Biol Mood Anxiety Disord 2011;1:3

98. Taylor WD, Kuchibhatla M, Payne ME, Macfall JR, Sheline YI, Krishnan KR, Doraiswamy PM. Frontal white matter anisotropy and antidepressant remission in late-life depression. PLoS One 2008;3:e3267.

99. Nobuhara K, Okugawa G, Minami T, Takase K, Yoshida T, Yagyu T, Tajika A, Sugimoto T, Tamagaki C, Ikeda K, Sawada S, Kinoshita T. Effects of electroconvulsive therapy on frontal white matter in late-life depression: a diffusion tensor imaging study. Neuropsychobiology 2004;50:48-53

100. Kozel FA, Johnson KA, Nahas Z, Nakonezny PA, Morgan PS, Anderson BS, Kose S, Li X, Lim KO, Trivedi MH, George MS. Fractional anisotropy changes after several weeks of daily left high-frequency repetitive transcranial magnetic stimulation of the prefrontal cortex to treat major depression. J ECT 2011;27:5-10.

101. Bezerra DM, Pereira FR, Cendes F, Jackowski MP, Nakano EY Moscoso MA, Ribeiz SR, Avila R, Castro CC, Bottino CM. DTI voxelwise analysis did not differentiate older depressed patients from older subjects without depression. J Psychiatr Res 2012;46:1643-9.

102. Abe O, Yamasue H, Kasai K, Yamada H, Aoki S, Inoue H, Takei K, Suga M, Matsuo K, Kato T, Masutani Y, Ohtomo K. Voxel-based analyses of gray/white matter volume and diffusion tensor data in major depression. Psychiatry Res 2010;181:64-70.

103. Kieseppä T, Eerola M, Mäntylä R, Neuvonen T, Poutanen VP, Luoma K, Tuulio-Henriksson A, Jylha P, Mantere O, Melartin T, Rytsala H, Vuorilehto M, Isometsa E. Major depressive disorder and 
white matter abnormalities: a diffusion tensor imaging study with tract-based spatial statistics. J Affect Disord 2010;120:240-4.

104. Weber K, Giannakopoulos P, Delaloye C, de Bilbao F, Moy G, Ebbing K, Moussa A, Herrmann FR, Gold G, Canuto A. Personality traits, cognition and volumetric MRI changes in elderly patients with early-onset depression: a 2-year follow-up study. Psychiatry Res 2012;198:47-52.

105. Weber K, Giannakopoulos P, Delaloye C, de Bilbao F, Moy G, Moussa A, Rubio MM, Ebbing K, Meuli R, Lazeyras F, Meiler-Mititelu C, Herrmann FR, Gold G, Canuto A. Volumetric MRI changes, cognition and personality traits in old age depression. J Affect Disord 2010;124:275-82.

106. Serafini G, Pompili M, Innamorati M, Fusar-Poli P, Akiskal HS, Rihmer Z, Lester D, Romano A, de Oliveira IR, Strusi L, Ferracuti S, Girardi P, Tatarelli R. Affective temperamental profiles are associated with white matter hyperintensity and suicidal risk in patients with mood disorders. J Affect Disord 2011;129:47-55.

107. Rihmer A, Rozsa S, Rihmer Z, Gonda X, Akiskal KK, Akiskal HS. Affective temperaments, as measured by TEMPS-A, among nonviolent suicide attempters. J Affect Disord 2009;116:18-22.

108. Picerni E, Petrosini L, Piras F, Laricchiuta D, Cutuli D, Chiapponi C, Fagioli S, Girardi P, Caltagirone C, Spalletta G. New evidence for the cerebellar involvement in personality traits. Front Behav Neurosci 2013; 7:133.

109. Laricchiuta D, Petrosini L, Piras F, Macci E, Cutuli D, Chiapponi C, Cerasa A, Picerni E, Caltagirone C, Girardi P, Tamorri SM, Spalletta G. Linking novelty seeking and harm avoidance personality traits to cerebellar volumes. Hum Brain Mapp 2014;35:285-96.

110. Bjørnebekk A, Westlye LT, Fjell AM, Grydeland H, Walhovd KB. Social reward dependence and brain white matter microstructure. Cereb Cortex 2012;22:2672-9.

111. Westlye LT, Bjørnebekk A, Grydeland H, Fjell AM, Walhovd KB. Linking an anxiety-related personality trait to brain white matter microstructure: diffusion tensor imaging and harm avoidance. Arch Gen Psychiatry 2011;68:369-77.

112. Van Schuerbeek P, Baeken C, De Raedt R, De Mey J, Luypaert R. Individual differences in local gray and white matter volumes reflect differences in temperament and character: a voxel-based morphometry study in healthy young females. Brain Res 2011;1371:32-42.

113. Kaasinen V, Maguire RP, Kurki T, Brück A, Rinne JO. Mapping brain structure and personality in late adulthood. Neuroimage 2005;24:315-22.

114. Krishnan KR, McDonald WM. Arteriosclerotic depression. Med Hypotheses 1995;44:111-5.

115. Alexopoulos GS, Meyers BS, Young RC, Campbell S, Silbersweig D, Charlson M. 'Vascular depression' hypothesis. Arch Gen Psychiatry 1997;54:915-22.

116. Lenze E, Cross D, McKeel D, Neuman RJ, Sheline YI. White matter hyperintensities and gray matter lesions in physically healthy depressed subjects. Am J Psychiatry 1999;156:1602-7.

117. Inzitari D, Simoni M, Pracucci G, Poggesi A, Basile AM, Chabriat H, Erkinjuntti T, Fazekas F, Ferro JM, Hennerici M, Langhorne P, O'Brien J, Barkhof F, Visser MC, Wahlund LO, Waldemar G, Wallin A, Pantoni L, Group LS. Risk of rapid global functional decline in elderly patients with severe cerebral age-related white matter changes: the LADIS study. Arch Intern Med 2007;167:81-8.

118. Steffens DC, Bosworth HB, Provenzale JM, MacFall JR. Subcortical white matter lesions and functional impairment in geriatric depression. Depress Anxiety 2002;15:23-8.

119. Steffens DC, Potter GG, McQuoid DR, MacFall JR, Payne ME, Burke JR, Plassman BL, Welsh-Bohmer KA. Longitudinal magnetic resonance imaging vascular changes, apolipoprotein $\mathrm{E}$ genotype, and development of dementia in the neurocognitive outcomes of depression in the elderly study. Am $J$ Geriatr Psychiatry 2007; 15:839-49.

120. Teodorczuk A, O’Brien JT, Firbank MJ, Pantoni L, Poggesi A, Erkinjuntti T, Wallin A, Wahlund LO, Gouw A, Waldemar G, Schmidt R, Ferro JM, Chabriat H, Bazner H, Inzitari D, Group L. White matter changes and late-life depressive symptoms: longitudinal study. Br J Psychiatry 2007;191:212-7.

121. Teodorczuk A, Firbank MJ, Pantoni L, Poggesi A, Erkinjuntti T, Wallin A, Wahlund LO, Scheltens P, Waldemar G, Schrotter G, Ferro JM, Chabriat H, Bazner H, Visser M, Inzitari D, O'Brien JT. Relationship between baseline white-matter changes and development of late-life depressive symptoms: 3-year results from the LADIS study. Psychol Med 2010;40:603-10.

122. Jollant F, Lawrence NS, Giampietro V, Brammer MJ, Fullana MA, Drapier D, Courtet P, Phillips ML. Orbitofrontal cortex response to angry faces in men with histories of suicide attempts. Am J Psychiatry 2008; $165: 740-8$

123. Jia Z, Huang X, Wu Q, Zhang T, Lui S, Zhang J, Amatya N, Kuang W, Chan RC, Kemp GJ, Mechelli A, Gong Q. High-field magnetic resonance imaging of suicidality in patients with major depressive disorder. Am J Psychiatry 2010;167:1381-90.

124. Hopkinson G. A genetic study of affective illness in patients over 50 . Br J Psychiatry 1964;110:244-54.

125. Schulz B. A statistical analysis of mental disorders in the families of manic-depressives grouped by age and sex. Arch Psychiatr Nervenkr Z Gesamte Neurol Psychiatr 1951;186:560-76.

126. Post F. Dementia, depression and pseudodementia. In: Benson DF, Blumer D, editors. Psychiatric Aspects of Neurologic Disease. New York: Grune and Stratton; 1975. p. 99-120.

127. Komaki S, Nagayama H, Ohgami H, Takaki H, Mori H, Akiyoshi J. Prospective study of major depressive disorder with white matter hyperintensity: comparison of patients with and without lacunar infarction. Eur Arch Psychiatry Clin Neurosci 2008;258:160-4.

128. Dupont RM, Jernigan TL, Butters N, Delis D, Hesselink JR, Heindel W, Gillin JC. Subcortical abnormalities detected in bipolar affective disorder using magnetic resonance imaging. Clinical and neuropsychological significance. Arch Gen Psychiatry 1990;47:55-9.

129. McDonald WM, Tupler LA, Marsteller FA, Figiel GS, DiSouza S, Nemeroff CB, Krishnan KR. Hyperintense lesions on magnetic resonance images in bipolar disorder. Biol Psychiatry 1999;45:965-71.

130. Figiel GS, Krishnan KR, Rao VP, Doraiswamy M, Ellinwood EH Jr, Nemeroff CB, Evans D, Boyko O. Subcortical hyperintensities on brain magnetic resonance imaging: a comparison of normal and bipolar subjects. J Neuropsychiatry Clin Neurosci 1991;3:18-22.

131. Ringelstein EB, Kleffner I, Dittrich R, Kuhlenbäumer G, Ritter MA. Hereditary and non-hereditary microangiopathies in the young. An up-date. J Neurol Sci 2010;299:81-5.

132. Sprooten E, Sussmann JE, Clugston A, Peel A, McKirdy J, Moorhead TW, Anderson S, Shand AJ, Giles S, Bastin ME, Hall J, Johnstone EC, Lawrie SM, McIntosh AM. White matter integrity in individuals at high genetic risk of bipolar disorder. Biol Psychiatry 2011;70:350-6. 